Journal of

Strategic Management

(JSM)



Knowledge Acquisition and Resource Exploitation of Indigenous Oil and Gas Companies in Niger Delta, Nigeria Maclayton, Teinbo Isoboye

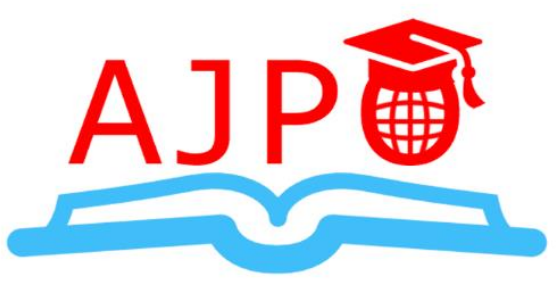




\title{
Knowledge Acquisition and Resource Exploitation of Indigenous Oil and Gas Companies in Niger Delta, Nigeria
}

\author{
Maclayton, Teinbo Isoboye \\ Department of Management, Faculty of Management Sciences, Rivers, State University, \\ Nkpolu-Oroworukwo, PMB 5080, Port Harcourt, Nigeria
}

E-mail: tmaclayton@gmail.com

\begin{abstract}
This study examined the relationship between knowledge acquisition and resource exploitation of indigenous oil and gas service companies in Niger Delta, Nigeria. Primary data was generated through structured questionnaire. The methodology used was quantitative and a cross-sectional survey method was adopted in the investigation of the study variables. The population of this study consisted of 332 (Three Hundred and Thirty Two) staff members of 26 highly functional/ active operational indigenous oil and gas service companies operating in the Niger Delta region of Nigeria. A sample size of 181 was determined using Taro Yamen sample size determination formula. The reliability of the instrument was achieved by the use of the Cronbach Alpha coefficient with all the items scoring above 0.70 . The hypotheses were tested using the Spearman's Rank Order Correlation Coefficient with the aid of the Statistical Package for the Social Sciences version 22.0. The findings of the study revealed that there is a significant relationship between knowledge acquisition and resource exploitation of indigenous oil and gas service companies in Niger Delta, Nigeria. The study recommends that indigenous oil and gas companies should foster relationships with critical stakeholders such as customers and suppliers and develop networks that may bring valuable information to the company, and opportunities to get new ideas from external parties should never be neglected. The managerial implications follow that if a firm enjoys a broad and connected client network it can facilitate the emergence of ambidexterity by stimulating higher levels of trust internally. However, if this firm is heavily dependent on teams to develop ambidextrous abilities in a self-managing and contextual fashion, trust may prove to be detrimental.
\end{abstract}

Keywords: Knowledge Acquisition, Resource Exploitation, Refinement, Continuous Improvement 


\section{INTRODUCTION}

Between 1912 and 1995, a study carried out by Hannah (1997) on the world's largest companies, revealed that only a few organizations were able to survive, in which majority of the organizations were those into natural resources without an experience of disruptive change. With regards to organizations that operate within the space of natural resources, it can be agreed that these organizational failures relate the same situation for indigenous oil and gas service companies in Nigeria, as hardly will you find any indigenous oil and gas service company that has long-survived through the turbulent political climates, global disruptive changes and increased global service demands even when they have all the resources (financial, intellectual and physical). This has long been the basic problem confronting indigenous oil and gas service companies in Nigeria as they have failed to exploit their internal resources and capabilities to ensure its current viability and at the same time, explore external resources and opportunities to ensure its future viability (March, 1991), hence the principal significance of this study. Addressing this problem in a seminar article March (1991) noted that the long survival of an organization is tied to the ability of the organization to exploit its existing assets and capabilities and simultaneously provide for exploration of new market opportunities in order to remain relevant in the rapid changing global market coupled with the introduction of new technologies. March noted that the inability for organizations to both exploit and explore is the fundamental challenged faced by organizations in their quest for longrun survival. In his terms, the basic problem confronting an organization is to engage in sufficient exploitation to ensure its current viability and, at the same time devote enough energy to exploration to ensure its future viability (1991: 105). This can greatly be facilitated through knowledge acquisition.

The changing world of work has strikingly initiated the discourse on knowledge as a critical resource that strategically induce organization performance outcome. The thinking is that the human resource is imbued with knowledge that instigates his ability to contribute and undertake work tasks. Knowledge is the impetus for his acquired skills and competencies. The importance of knowledge has been underscored in strategic management literature therefore its management has assumed same dosage in the discourse (Helfert \& Liberman, 2002; Trispas, 2009). Knowledge management as a process involves acquisition, refinement, storage, transfer and sharing within organization thus representing a dynamic competitive resource as espoused in the knowledge base view of Gilsby, (2007). It has also been defined by Scaborough (2008) that it is the process of creating, acquiring, capturing and sharing knowledge whenever it is found. Egbu (2001) had considered strongly that in all of these processes, the need to acquire it is a strong concern for all members of the organization. Acquiring knowledge is a candidly initiated effort to strategically alter attempt at competitiveness with a view to ensuring dominance among competitors.

Billa (2006) opined that knowledge seeking firms are operational string to the extent that they sufficiently share through structural flexibility and infrastructure that facilitate sharing. These positions suggest the premium ascribed to firms ability to acquire knowledge for all purposes. Prahlad and Hammel (2002) relying on the knowledge based view had noted that competencies are seen as the basis for a company's ability to acquire competitive advantage. They had further observed that employees improved work action in relation to assigned responsibilities is not a 
function of tangible or extrinsic incentives or the conducive work environment rather, the today's worker characteristically acquire knowledge which constitute the asset that reengineer all work processes towards goals. As earlier noted, the acquisition component of the entire knowledge management process is fundamental as it precedes other activities in the entire knowledge management spectrum.

Rendenick (2008) had considered knowledge spread among employees as being a significant practice especially within tacit classification of knowledge. The argument put forward here is that since knowledge is in built within the individuals, it will require germane organizational platform created to help in its acquisition. To achieve this Renderick believed that a continuous interaction platform that will help in knowledge sharing and transfer is important for knowledge acquisition and sharing. This is in addition to the authors thinking that the sources from which the individual acquire knowledge and share it is also imperative for quality knowledge that meets the goals of building intellectual capital that is sustainable for competitiveness. Ewang (2006) noted that to generate employee support for organizational success, knowledge acquisition provides the strategic leverage that is empowering both in psychological and practical context of work. The willingness to acquire and strengthen what is eventually shared as shown in literature had seemingly shown the link between knowledge acquisition and several work outcomes. Therefore, this study examined the relationship between knowledge acquisition and resource exploitation of indigenous oil and gas companies in Niger Delta, Nigeria

This study was also guided by the following research questions:

i. What is the relationship between knowledge acquisition and refinement of indigenous oil and gas companies in Niger Delta, Nigeria?

ii. What is the relationship between knowledge acquisition and continuous improvement of indigenous oil and gas companies in Niger Delta, Nigeria?

iii. What is the relationship between knowledge acquisition and efficiency of indigenous oil and gas companies in Niger Delta, Nigeria? 


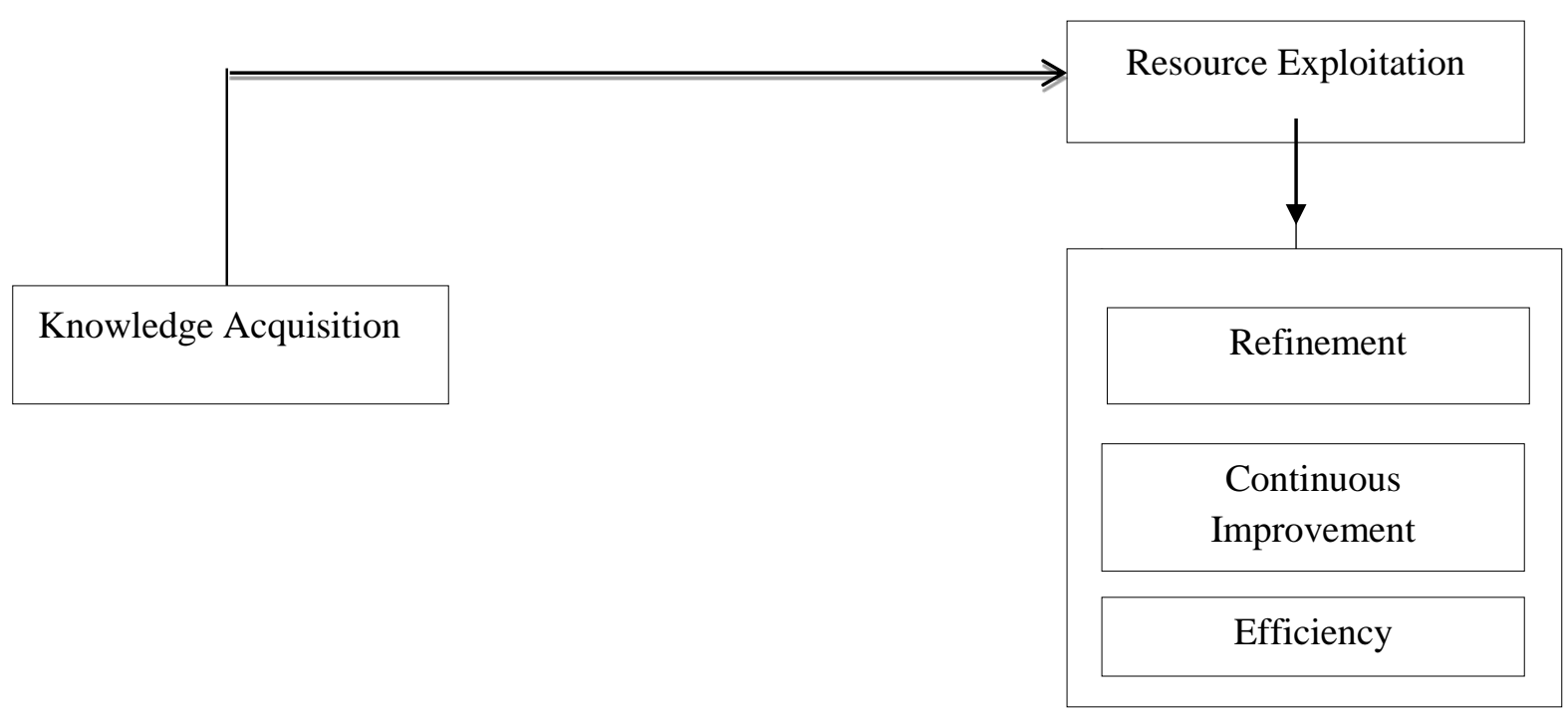

Fig.1 Conceptual framework for the relationship between knowledge acquisition and resource exploitation

Source: Author's Desk Research, 2019

\section{LITERATURE REVIEW}

\section{Knowledge Acquisition}

Acquisition signifies the capability of an organization in terms of identification and acquisition of knowledge generated externally, which is relevant to the operations within the organization. Zahra and George (2002) in their dimensions of ACAP exposed some components, roles and importance of acquisition which have been extracted from various authorities (Cohen \& Levinthal, 1990; Kim, 1998), the components are: prior investments, prior knowledge, intensity, speed and direction; while the roles and importance are: scope of search, perceptual scheme, new external connections, speed in which learning occurs and quality of learning. Zack (2015) argued that acquisition, capturing or gathering is bringing knowledge into the organization either through the generation of new knowledge through internal sources such as day to-day experiences or staff expertise, or accessing valuable knowledge from external information sources and other organizations. Knowledge acquisition is a complementary capability that enhances a firm's absorptive capability to identify and acquire external information that is critical to its operations (Zahra \& George, 2002). Darroch (2003) argues that knowledge acquisition relates to the location, creation or discovery of knowledge. The new knowledge in an organization has to either be invented internally or acquired from external sources. There are many sources of knowledge both internal and external for an organization to tap from (Werra et al. 2009 cited in Muchanji \& Makokha, 2009). Internally, employees' individual capabilities, skills and experiences need to be discovered and exploited. In the same way, externally, customers and channel members have knowledge that needs to be acquired by the organization for decision-making. Knowledge can also be acquired from other 
members of the external environment like competitors and the public (Petruzzelli, Albino \& Carbonara, 2009).

\section{Resource Exploitation}

Resource exploitation is characterized as one of the two activities causing tensions in the contest for organizational resource allocation, which involves refinement, efficiency, selection and implementation (March, 1991). In the views of Green (1999), exploitation involves the 'continuous improvement' of existing products and services, elimination of waste and ensures a highly efficient use of resources through flat organizational structures, teamwork, and co-operative supply chain management. Thus, in this context, Lavie, Stettner and Tushman (2010) suggest that exploitation is mainly associated with developing the organization's existing knowledge base. They further posit as long as the organization persists within an existing technological trajectory and leverages its existing skills and capabilities, its operations are geared toward exploitation (March, 1991). A typical example of this exploitation activity is the Swiss-watch manufacturers' transition from hand-wound style of watches to the automatic style of watches; this is a clear demonstration of the development of their existing mechanical engineering capabilities (Landes, 1983).

March (1991:71) defined exploitation as refinement, choice, production, efficiency, selection, implementation and execution, also March (1993) viewed exploitation as "the use and development of things already known". He further buttressed that organizations will display more value for efficiency over flexibility, and also seek for refinement of their existing processes as against carrying out search for new methods and processes (March, 1991). In the works of Green (1999) in the context of organizational exploitative activities, he noted that the main objectives of most organizations will be aimed at the continuous improvement of existing products, develop methods to eliminate waste and ensure efficiency in usage of resource, through the adoption of flat organization structures, successful teamwork, and cooperative supply chain management. Thus for this study, the three indicators of resource exploitation, which is one of the measures of organizational ambidexterity was drawn from Green's (1999) continuous improvement and March's (1991) refinement and efficiency.

\section{Measures of Resource Exploitation}

\section{Refinement}

Extant research has revealed that resource and organizational capability refinement increase the organization's performance and competitiveness by providing support to organizations in moving into better profitable product and service positions (Krishnan, Joshi, \& Krishnan, 2004), product positions that are new to the organization (Shelton, 1988), and also developing product markets (Uhlenburck, Hitt \& Semadeni, 2006). Consequently, current research suggests that organizations perform better when they are able to refine their capabilities and thereby provide or offer their market access to services or experiences not previously provided (Hitt, Harrison, Ireland, \& Best, 1998). 
Organizational management research has further shown that via the continuous use of organizational routines, organizations refine routines, thereby identifying and filtering out the less useful activities or those that failed to give the desired output (Nelson \& Winter, 1982). Amid each successive execution of refinement processes and the re-configuration of capabilities or resources, organizational members' beliefs and learning behaviours are enhanced and entrenched (Cyert \& March, 1963). As managers' though processes become more amenable through learning, managers' perceptual filters become tend to be more open and flexible, supporting and allowing for a greater quantity of extraneous information (Hambrick \& Mason, 1984). Furthermore, the organizational culture becomes more heterogenous leading to a progression towards change receptivity and increase in variety, inquiry, and experimentation (March, 1991). Thus, organizations become more flexible and are able to adapt to various changes in their environment.

\section{Efficiency}

The improvement of resource efficiency saves energy and is a major contributor of reduction in the consumption of primary resources and will lead to reduction in the volume of waste (Worrell, Bode, de Beer, 1997). In line with the previous discussion about refinement, resource efficiency offers the organization the control and streamlining of the application of its resources in such a way that is conservative. In this way unnecessary use of material or material losses in a defined system can be quantified as a percentage share, which is e.g. the case in automated processes during discrete part production.

One generic way of quantifying resource efficiency is given by Schaltegger, Bennet, Burrit and Jasch (2008). Using a rate measure and relating economic performance to a unit of resources use, the resource efficiency of a product, process or production function can be calculated. The resource efficiency of a function can, for example, be the contribution margin divided by the resource use per product of an assembly or automated system operating in production. This definition allows for considering all kinds of resources with respect to their economic impact. In fact, the scope of this measure deals with strategies for cleaner production and addresses the system level of environmental management accounting. Consequently, the handled information is rather aggregated compared to the scope of operational resources.

\section{Continuous Improvement}

Continuous Improvement $(\mathrm{CI})$ is a process that is being used worldwide by organizations as a strategy that satisfies the highly demanding global market in products and services. From existing literatures (Zangwill \& Kantor, 1998), it is evident that CI displays a broad variety of tools and approaches that yields improvement in production processes. According to Muhammed, Kabiru, Abdulkarim, Riazi and Nawi (2016: 300), "CI process is unique to every organization; the application should be in accordance with the nature of its activities". In recent literatures, the application of these CI theories or principles or a mixture of such principles and theories is also known to be best practice. Over the years, CI has played a critical role in the history of manufacturing as organizations continually seek for improved methods to carry out their daily activities and operations. 
In the historical review of extant literature, there has been no definite definition for CI, various authors have described it as either a process, a philosophy or a methodology; for example: CI as has been defined by Caroly, Coutarel, Landry and Mary-Cheray (2010) as "a process that aims to optimize information, physical flows and products in order to control production costs and quality". Bhuiyan and Baghel (2005) views CI as a culture of sustained improvement, which aims at eliminating waste in all processes and functions within the organization. Form the views of Bessant (2001) CI is a precise collection of practices or absorbed culture, which can aid the improvement of an organizations current activities or operations. In the views of Imai (1987) cited by Bessant (2001), CI is the Japanese culture called "kaizen". In the views of Zangwill \& Kantor (1998), CI is a collection of systematic influential practices tailored towards developing significant improvements in organizations.

\section{Knowledge Acquisition and Resource Exploitation}

Knowledge acquisition is associated to the discovery or creation of knowledge (Siggelkow \& Levinthal, 2003). It has been observed by researchers that policies, structures and processes are developed by organizations to advance learning and knowledge acquisition Knowledge acquisition is associated to the discovery or creation of knowledge (Siggelkow \& Levinthal, 2003). There are various sources from which knowledge can be acquired and they are also of great diversity. Thus, each source might have relationships with an extensive range of issues an organization can face (Rosenkopft \& Nerkar, 2001). Acquisition of knowledge can be from outside the organization such as inter-organizational relationships, strategic alliances, social networks, competitors and also customers or it could be from inside the organization such as individuals in the form of prior acquired skills and experiences. The acquired knowledge might be in the form of data and/or information about its competitor's products, services or processes, technological advancement or other similar information that will add value to the organization (Gupta, Smith, \& Shalley, 2006).

In terms of refinement, which is a form of renewal of organizational processes and structures with the aim of new or improved value creation to the organizations existing competence or resources, it could be agreed that the knowledge acquired by organizations (internal or external) can refine the organization if only it adds value to the organizations existing competences or resources. The acquisition of knowledge is linked with learning, and learning is a way of adding value by gaining new individual or organizational competence that leads to a refined personnel or organization.

In terms of continuous improvement, which is the improvement of processes with a focus of eliminating waste, seeking innovative approaches to improve organizational performance and reduce organizational failures; appropriate knowledge acquired will drive the process of organizational continuous improvement. This knowledge acquired could be in the form of benchmarking similar organizational or industry processes, operational methodologies and organizational structures in order to be aligned with the related industry best practices.

In terms of efficiency, which entails deliverables under time, energy and cost minimization; the acquired knowledge from an organizations external or internal environment that contains information on how to minimize time, energy and cost, but still achieve or exceed the desired 
organizational deliverables by the best possible use of available resources can lead to organizational efficiency.

From the foregoing arguments, the study thus hypothesized that:

Ho1: There is no significant relationship between knowledge acquisition and refinement of indigenous oil and gas companies in Niger Delta, Nigeria.

Ho2: There is no significant relationship between knowledge acquisition and continuous improvement of indigenous oil and gas companies in Niger Delta, Nigeria.

Ho3: There is no significant relationship between knowledge acquisition and efficiency of

\section{METHODOLOGY}

Primary data was generated through structured questionnaire. The methodology used was quantitative and a cross-sectional survey method was adopted in the investigation of the study variables. The population of this study consisted of 332 (Three Hundred and Thirty Two) staff members of 26 highly functional/ active operational indigenous oil and gas service companies operating in the Niger Delta region of Nigeria. A sample size of 181 was determined using Taro Yamen sample size determination formula. The reliability of the instrument was achieved by the use of the Cronbach Alpha coefficient with all the items scoring above 0.70. The hypotheses were tested using the Spearman's Rank Order Correlation Coefficient with the aid of the Statistical Package for the Social Sciences version 22.0.

\section{DATA ANALYSIS AND RESULTS}

Data analysis was carried out using the Spearman rank order correlation tool at a $95 \%$ confidence interval. Specifically, the tests cover the hypotheses that were bivariate and declared in the null form. We have based on the statistic of Spearman Rank (rho) to carry out the analysis.

\begin{tabular}{|c|c|c|c|c|c|c|}
\hline & & & Acquisition & Refine & Improve & Efficient \\
\hline \multirow{12}{*}{$\begin{array}{l}\text { Spearman's } \\
\text { rho }\end{array}$} & \multirow{3}{*}{ Acquisition } & Correlation Coefficient & 1.000 & $.631^{\text {** }}$ & $.658^{* *}$ & $.593^{* * *}$ \\
\hline & & Sig. (2-tailed) & . & .000 & .000 & .000 \\
\hline & & $\mathrm{N}$ & 179 & 179 & 179 & 179 \\
\hline & \multirow{3}{*}{ Refine } & Correlation Coefficient & $.631^{* *}$ & 1.000 & $.661^{* *}$ & $.443^{* *}$ \\
\hline & & Sig. (2-tailed) & .000 & - & .000 & .000 \\
\hline & & $\mathrm{N}$ & 179 & 179 & 179 & 179 \\
\hline & \multirow{3}{*}{ Improve } & Correlation Coefficient & $.658^{* *}$ & $.661^{* *}$ & 1.000 & $.616^{* *}$ \\
\hline & & Sig. (2-tailed) & .000 & .000 & & .000 \\
\hline & & $\mathrm{N}$ & 179 & 179 & 179 & 179 \\
\hline & \multirow{3}{*}{ Efficient } & Correlation Coefficient & $.593^{* *}$ & $.443^{* *}$ & $.616^{* *}$ & 1.000 \\
\hline & & Sig. (2-tailed) & .000 & .000 & .000 & \\
\hline & & $\mathrm{N}$ & 179 & 179 & 179 & 179 \\
\hline
\end{tabular}

Source: SPSS Output 
The results for the tests reveal knowledge acquisition significantly impacts on the six measures of resource exploitation (refinement, continuous improvement and efficiency). The results are detailed as follows:

\section{$H_{o 1}:$ There is no significant relationship between knowledge acquisition and refinement of indigenous oil and gas companies in Niger Delta, Nigeria.}

From the result in the table above, the correlation coefficient (rho) shows that there is a significant relationship between knowledge acquisition and refinement. The correlation coefficient 0.631 confirms the magnitude and strength of this relationship and it is significant at $p 0.000<0.01$. The correlation coefficient represents a high correlation indicative of a very strong relationship between the variables. Therefore, based on empirical findings the null hypothesis earlier stated is hereby rejected and the alternate upheld. Thus, there is a significant relationship between knowledge acquisition and refinement of indigenous oil and gas companies in Niger Delta, Nigeria.

\section{$H_{o 2:}$ There is no significant relationship between knowledge acquisition and refinement of indigenous oil and gas companies in Niger Delta, Nigeria.}

From the result in the table above, the correlation coefficient (rho) shows that there is a significant relationship between knowledge acquisition and continuous improvement. The correlation coefficient 0.658 confirms the magnitude and strength of this relationship and it is significant at $\mathrm{p}$ $0.000<0.01$. The correlation coefficient represents a high correlation indicative of a strong relationship between the variables. Therefore, based on empirical findings the null hypothesis earlier stated is hereby rejected and the alternate upheld. Thus, there is a significant relationship between knowledge acquisition and continuous improvement of indigenous oil and gas companies in Niger Delta, Nigeria.

\section{$H_{o 3}:$ There is no significant relationship between knowledge acquisition and refinement of indigenous oil and gas companies in Niger Delta, Nigeria.}

From the result in the table above, the correlation coefficient (rho) shows that there is a significant relationship between knowledge acquisition and efficiency. The correlation coefficient 0.593 confirms the magnitude and strength of this relationship and it is significant at $p 0.000<0.01$. The correlation coefficient represents a moderate correlation indicative of a moderate relationship between the variables. Therefore, based on empirical findings the null hypothesis earlier stated is hereby rejected and the alternate upheld. Thus, there is a significant relationship between knowledge acquisition and efficiency of indigenous oil and gas companies in Niger Delta, Nigeria.

\section{DISCUSSION OF FINDINGS}

The relationship between knowledge acquisition and resource exploitation was observed to be significant. This observation follows the position of researchers from different research areas which have been varying the challenge of acquiring knowledge externally while integrating that knowledge into internal organization (Raisch, Probst \& Tushman, 2009). The current knowledge marketplace is an evolving economy characterized by new technologies, globalization, and an 
ever-increasing emphasis on intangible services (Neef, 1998). Strategy scholars, business gurus, pundits and management researchers suggest that today's marketplace is knowledge-based. Knowledge and the competencies built upon this platform must be the main factor in determining an organization's current and future value (Drucker, 1993; Grant, 1996). As such, the 1980's view of capital, natural resources, and labour are no longer considered the most valuable resources in today's global economy. Rather, knowledge and knowledge workers play the central role (Drucker, 1993). Knowledge has emerged as the most strategically significant resource of the organization as increasing turbulence of the external business environment has focused attention upon resources and organizational capabilities (Grant, 1996).

When knowledge is locally derived, the ability of a firm is enhanced by adapting products to local product markets, identifying technological changes that impact firm performance, and capitalizing on market dynamism through new product developments (Ghoshal, 1987). The global success of oil and gas firms, especially those indigenous to Nigeria, is attributable to the key resources that they are able to leverage when expanding to new markets. Nowhere is this more evident than in transitional economies, where other organizations have engaged in technology transfer within their foreign direct investments (Radosevic, 1999).

The position of this study is that knowledge acquisition is an important part of the process of increasing absorptive capacity, because that is the way to bring in new knowledge into an enterprise. This new knowledge forms the basis for future innovation activities and affects other creative capabilities, knowledge exploitation, and future absorptive capacity. Two basic types of knowledge acquisition are market knowledge acquisition (direct and indirect) and technological knowledge acquisition. Although every enterprise has got so called static stock of knowledge, based on its human resources, new "flows of knowledge" should also be formed for knowledge acquisition. The reason for this is learning about new market chances and technological perspectives. Introducing the key needs and market requests to the management improves an enterprise's innovative ability in the future period. The same goes for new technological knowledge acquisition.

A firm's size is an important factor for technological knowledge acquisition because this usually is an expensive activity. Saemundsson (2005) claimed that there is a pressure in small and new enterprises between possible benefits from new technological knowledge acquisition and its costs (Saemudsson, 2005). Therefore, having a critical amount of capital and human resources (and other benefits coming with the enterprise's size) can help the financing activity for technological knowledge acquisition. In order to explain and understand the process of knowledge acquisition, it is necessary to consider other internal factors in an organizational, but also the external factors in the environment.

Considering knowledge acquisition in technologically advanced enterprises' sample, researchers (Yli-Renko, Autio, and Sapienza, 2001) recognized the following factors as relevant: social interaction, networks and relationships with clients, technological specificity of products on the market and other. Similar to that, Smith, Collins and Clark note that the strength of relationships with clients, as well as the level of employees' education is very important for knowledge acquisition (Smith, Collins and Clark, 2005). 


\section{CONCLUSION AND RECOMMENDATION}

In conclusion, this study concludes that that knowledge acquisition has a strong, statistically significant and positive influence on resource exploration and exploitation activities of indigenous oil and gas firms in the Niger Delta. An organization that is capable of acquiring knowledge from different external sources of information will therefore be more successful in balancing its explorative. Such an organization will be even more successful in increasing their range of goods or services, increasing their market or market share and improving the quality of their goods and services.

The study recommends that indigenous oil and gas companies should foster relationships with critical stakeholders such as customers and suppliers and develop networks that may bring valuable information to the company, and opportunities to get new ideas from external parties should never be neglected. The managerial implications follow that if a firm enjoys a broad and connected client network it can facilitate the emergence of ambidexterity by stimulating higher levels of trust internally. However, if this firm is heavily dependent on teams to develop ambidextrous abilities in a self-managing and contextual fashion, trust may prove to be detrimental.

\section{REFERENCES}

Bessant, J. (2001). An evolutionary model of continuous improvement behavior. Technovation, 21, 67-77.

Billa, J. O. (2006). Motivating for compliance in knowledge management scheme for on-the-shop floor employees. Journal of Management, 15(7), 92-108.

Bhuiyan, N. \& Baghel, A. (2005). An overview of continuous improvement from the past to the present. Measurement Decision, 13, 761-771.

Cohen, W. M. \& Levinthal, D. A. (1990). Absorptive capacity: A new perspective on learning and innovation. Administrative Science Quarterly, 35(1), 128-152.

Cyert, R.M. \& March, J.G. (1963). A Behavioral Theory of the Firm. Englewood Cliffs, NJ: Prentice-Hall.

Drucker, P.F. (1993). Post-Capitalist Society. Oxford, UK: Butterworth-Heinemann

Egbu, C. O. (2001). Knowledge management and HRM: The role of the Project Manager. Proceedings of PMI Europe 2001 - A Project Management Odyssey, 6 - 7th June 2001, Café Royal, London, UK.

Ewang, F. P. (2005). Intellectual capital fit among medium organizations. Journal of Innovation Science, 42(8), 773-792.

Gilsby, O. (2007). Intellectual capital management and competitiveness among ICT support firms. Journal of Information Technology, 7(11), 67-83. 
Ghoshal, S. (1987). Global strategy an organizing framework. Strategic Management Journal, 8, 425-440.

Grant, R.M. (1996a). Towards a knowledge-based theory of the firm. Strategic Management Journal, 17.Special Issue entitled Knowledge and the Firm

Gupta, A. K., Smith, K. G. \& Shalley, C. E. (2006). The interplay between exploration and exploitation. Academy of Management Journal, 49(4), 693-706. http:// dx.doi.org/ 10.5465/AMJ.2006.22083026.

Hambrick, D. C. \& Mason, P. A. (1984). Upper echelons: The organization as a reflection of its top managers. The Academy of Management Review, 9(2), 193-206.

Hannah, L. (1997). Marshall's trees and the global forest: Were giant redwoods different? Center for Economic Performance, Discussion Paper, 318.

Helfat, C. E. \& Liberman, M. B. (2002). The birth of capabilities: market entry and the importance of pre-history. Industrial and Corporate Change, 11(4), 725-760. http://dx.doi.org/10.1093/icc/11.4.725

Hitt, M. A., Harrison, J. R., Ireland, R. D. \& Best, A. (1998). Attributes of successful and unsuccessful acquisitions of U.S. firms. British Journal of Management, 9, 91-114.

Kim, L. (1998). Crisis construction and organizational learning: Capability building in catchingup at Hyundai Motor. Organization Science, 9, 506-521.

Krishnan, R.A., Joshi, S. \& Krishnan, H. (2004). The influence of mergers on firms' product mix strategies. Strategic Management Journal, 25(6), 587-611.

Lavie, D., Stettner, U. \& Tushman, M.L. (2010) Exploration and exploitation within and across organizations. Academy of Management Annals, 4, 109-155.

March, J. G. (1991).Exploration and exploitation in organizational learning. Organization Science, 2(1), 71-87.

Muchanji, W. J., \& Makokha, E. N. (2018). Effect of knowledge acquisition on competitiveness of savings and credit cooperative societies in Trans Nzoia County, Kenya. International Journal of Academic Research in Business and Social Sciences, 8(9), 716-734.

Nelson, R. \& Winter, S. (1982). An Evolutionary Theory of Economic Change. Cambridge: Harvard University Press.

Petruzzelli, A., Albino, V. \& Carbonara, N. (2009). External knowledge sources and proximity, Journal of Knowledge Management, 13(5), 301-318. 
Prahald, C. K. \& Hammel, G. (1990). The Core Competence of the Corporation. Harvard

Raisch, S., Birkinshaw, J., Probst, G. \& Tushman, M. L. (2009). Organizational ambidexterity: Balancing exploitation and exploration for sustained performance. Organization Science, 20(4), 685-695.

Rosenkopf, L. \& Nerkar, A. (2001). Beyond local search: Boundary spanning, exploration and impact in the optical disk industry. Strategic Management Journal, 22, 287-306.

Saemundsson, R. (2005). On the interaction between the growth process and the development of technical knowledge in young and growing technology-based firms. Technovation, $25,2005,223-235$.

Scaborogh, H. (2008). Knowledge Management: A Research. London: Bearly Pub.

Schaltegger, S.,Bennet, M., Burrit, R. L. \& Jasch, C. (2008). Environmental Management Accounting for Cleaner Production. Springer.

Siggelkow, N. \& Levinthal, D. (2003). Temporarily divide to conquer: centralized, decentralized, and reintegrated organizational approaches to exploration and adaptation. Organization Science, 14, 650-69.

Trispas, M. (2009). Technology, Identity, and Inertia through the lens of the digital photography company. Organization Science, 20(2), 441-460. Business Review, 68(3), 78-91.

Uhlenbruck, K., Hitt, M.A. \& Semadeni, M., 2006. Market value effects of acquisitions involving Internet firms: A resource-based analysis. Strategic Management Journal, 27(10), 899-913.

Worrell, E., Bode, J.W. \& de Beer, J.G. (1997). Energy efficient technologies in industry analysing research and technology development strategies - the 'atlas' project. Dept. of Science, Technology \& Society, Utrecht University, Utrecht, The Netherlands

Yli-Renko, H., Autio, E. \& Sapienza, H.J. (2001). Social capital, knowledge acquisition, and knowledge exploitation in young technology-based firms. Strategy Management Journal, 22, 587-613

Zangwill, W. Y. \& Kantor, P. (1998). Toward a theory of continuous improvement and the learning curve. Management Science, 44(7), 910-920.

Zahra, S. A. \& George, G. (2002). Absorptive capacity: A review, reconcepualisation, and extension. Academy of Management Review, 27(2), 185-203. 